\title{
Diagnostic Performance of Self-Reported Smell and Taste Disorders Varies with COVID-19 Prevalence in Primary Care Settings
}

J Gen Intern Med 36(12):3925-7

DOI: $10.1007 / \mathrm{s} 11606-021-07141-5$

() Society of General Internal Medicine 2021

\section{INTRODUCTION}

Studies in primary care, including our own, showed that patients with COVID-19 frequently complained of smell and/or taste disorders. ${ }^{1,2}$ This finding is possibly related to the tropism of SARS-CoV-2 for the nerves of the ENT system. ${ }^{3}$ In an epidemic context, the high specificity of these two symptoms, taken alone or in combination, could help primary care physicians (PCPs) in their diagnostic approach when examining patients suspected of having COVID-19. ${ }^{4}$ To our knowledge, the diagnostic contribution of these symptoms in low COVID-19 prevalence periods or settings $(<5 \%)$ is unknown.

We conducted a study in France with primary care patients to compare the diagnostic performance of smell and/or taste disorders in high versus low COVID-19 prevalence.

\section{METHODS}

This cross-sectional study was conducted between March 24 and June 9, 2020, in two French regions (Lyon and Marseille). Patients suspected of having COVID-19 were referred by their PCP to a medical laboratory (two in Lyon and six in Marseille) for nasopharyngeal RT-PCR testing. Before the test, patients answered a questionnaire on sociodemographic characteristics and the presence or absence of smell and taste disorders. We assessed the association between these symptoms and SARS-CoV-2 infection using logistic regression adjusted for gender, age group, and clustering within laboratories. Then, we examined the diagnostic performance of these symptoms by computing sensitivity, specificity, ROC area, and positive and negative likelihood ratios. All analyses were done for two periods (first period $=$ high prevalence of infection: March 24 to

Received June 30, 2021

Accepted September 3, 2021

Published online September 24, 2021
April 15; second period $=$ low prevalence: April 16 to June 9) using STATA 15.1 (College Station, USA).

\section{RESULTS}

We included 2514 consecutive patients $($ women $=59 \%$, median age $=43$ years (interquartile range $=28)$ ). There were 1543 patients recruited in Lyon (61\%) and 971 in Marseille (39\%). Overall, 272 patients tested positive for SARS-CoV-2 (11\%). The proportion of positive tests was $23 \%$ during the first period of data collection $(N$ $=224 / 971)$ and $3 \%$ during the second period $(N=48 /$ 1543). During the first period, the odds of positive testing was $>5$ times the odds of negative testing for smell and/or taste disorders in both univariable and multivariable analyses (Table 1). During the second period, the differences in odds were not statistically significant.

The diagnostic performance table shows several substantial differences between the two periods (Table 2). The overall performance (ROC area) for the individual or combined presence of these two symptoms decreased from $0.60-0.67$ for period 1 to $0.49-0.51$ for period 2 , and the positive likelihood ratio decreased from 3.0-4.4 to $0.8-1.4$ (with confidence intervals including 1).

\section{DISCUSSION}

In this primary care population, the overall performance (ROC area) and positive likelihood ratio of taste and/or smell disorders was 0.5 and close to 1 , respectively, in a period of low COVID-19 prevalence (test positivity rate $=3 \%$ ). These results suggest that the diagnostic test used (i.e., the presence of taste and/or smell disorders) has no discriminatory ability to diagnose patients with and without the condition (i.e., with a positive or negative RT-PCR test), and is therefore not useful for the diagnostic approach.

For example, among 63 patients reporting anosmia, 61 tested negative and only two tested positive (i.e., one test was positive for every 31 tests that were negative), and among 1457 patients without anosmia, there were 1411 negative tests and 46 positive tests (i.e., again a positive to negative test ratio of 1:31). 
Table 1 Association Between Smell and/or Taste Disorders, and Positivity of the SARS-CoV-2 RT-PCR Test

\begin{tabular}{|c|c|c|c|c|c|c|c|}
\hline Symptom & $\begin{array}{l}\text { Overall } \\
N(\%)\end{array}$ & $\begin{array}{l}\text { Patients with } \\
\text { a positive test } \\
N(\%)\end{array}$ & $\begin{array}{l}\text { Patients with } \\
\text { a negative test } \\
N(\%)\end{array}$ & $\begin{array}{l}\text { OR } \\
(95 \% \text { CI })\end{array}$ & $p$-value ${ }^{1}$ & $\begin{array}{l}\text { Adjusted } \\
\text { OR (95\% CI) }\end{array}$ & $p$-value ${ }^{2}$ \\
\hline First period of data collection ${ }^{3}$ & $N=970$ & $N=224$ & $N=746$ & & & & \\
\hline Smell disorder 4 & $190(19.6)$ & $94(42.0)$ & $96(12.9)$ & $4.9(4.2-5.7)$ & $<0.001$ & $5.1(4.3-6.1)$ & $<0.001$ \\
\hline Taste disorder ${ }^{5}$ & $166(17.1)$ & $83(37.1)$ & $83(11.1)$ & $4.7(3.9-5.7)$ & $<0.001$ & $5.1(4.0-6.6)$ & $<0.001$ \\
\hline Smell and taste disorder ${ }^{4,5}$ & $107(11.0)$ & $60(26.8)$ & $47(6.3)$ & $5.5(3.5-8.5)$ & $<0.001$ & $5.8(3.6-9.4)$ & $<0.001$ \\
\hline Smell or taste disorder ${ }^{4,5}$ & $249(25.7)$ & $117(52.2)$ & $132(17.7)$ & $5.1(4.5-5.8)$ & $<0.001$ & $5.5(4.7-6.4)$ & $<0.001$ \\
\hline Second period of data collection 6 & $N=1521$ & $N=48$ & $N=1472$ & & & & \\
\hline Smell disorder ${ }^{4}$ & $63(4.1)$ & $2(4.2)$ & $61(4.2)$ & $1.0(0.3-3.2)$ & 0.99 & $1.0(0.3-3.1)$ & 0.93 \\
\hline Taste disorder ${ }^{5}$ & $67(4.4)$ & $2(4.2)$ & $65(4.4)$ & $0.9(0.3-3.0)$ & 0.92 & $0.9(0.3-2.8)$ & 0.81 \\
\hline Smell and taste disorder 4,5 & $45(3.0)$ & $2(4.2)$ & $43(2.9)$ & $1.4(0.5-4.7)$ & 0.54 & $1.3(0.4-4.4)$ & 0.64 \\
\hline Smell or taste disorder 4,5 & $84(5.5)$ & $2(4.2)$ & $82(5.6)$ & $0.7(0.2-2.3)$ & 0.60 & $0.7(0.2-2.2)$ & 0.54 \\
\hline
\end{tabular}

${ }^{1}$ Univariable logistic regression (adjusted for clustering within laboratories)

${ }^{2}$ Multivariable logistic regression (adjusted for clustering within laboratories, gender, and age group)

${ }^{3}$ First period of data collection: March 24 to April 15, 2020

${ }^{4}$ Anosmia or hyposmia

${ }^{5}$ Ageusia or hypogeusia

${ }^{6}$ Second period of data collection: April 16 to June 9, 2020

Our study sample was not a random community sample. The prevalence of SARS-CoV-2 infection was probably higher in this population, which consisted of patients sent for laboratory testing by their PCP. Furthermore, the results of our study could theoretically be biased by the diagnostic performance of the RT-PCR test. However, this test seems to lead to very few false positive/negative results. A strength of our study is that it was conducted in the same conditions over

Table 2 Diagnostic Performance of Smell and/or Taste Disorders

\begin{tabular}{|c|c|c|c|c|c|}
\hline Symptom & Sensitivity (95\% CI) & Specificity $(95 \% \mathrm{CI})$ & $\begin{array}{l}\text { ROC area } \\
(95 \% \mathrm{CI})\end{array}$ & $\begin{array}{l}\text { Positive likelihood } \\
\text { ratio }(95 \% \mathrm{CI})\end{array}$ & $\begin{array}{l}\text { Negative } \\
\text { likelihood } \\
\text { ratio }(95 \% \mathrm{CI})\end{array}$ \\
\hline \multicolumn{6}{|l|}{ First period of data collection ${ }^{1}$} \\
\hline Smell disorder $^{2}$ & $42.0(35.4-48.7)$ & $87.1(84.5-89.5)$ & $\begin{array}{l}0.65(0.61- \\
0.68)\end{array}$ & $3.3(2.6-4.2)$ & $0.7(0.6-0.8)$ \\
\hline Taste disorder ${ }^{3}$ & $37.1(30.7-43.7)$ & $88.9(86.4-91.0)$ & $\begin{array}{l}0.63(0.60- \\
0.66)\end{array}$ & $3.3(2.6-4.3)$ & $0.7(0.6-0.8)$ \\
\hline Smell and taste disorder ${ }^{2,3}$ & $26.8(21.1-33.1)$ & $93.7(91.7-95.3)$ & $\begin{array}{l}0.60(0.57- \\
0.63)\end{array}$ & $4.3(3.0-6.0)$ & $0.8(0.7-0.9)$ \\
\hline Smell or taste disorder ${ }^{2,3}$ & $52.2(45.5-58.9)$ & $82.3(79.4-85.0)$ & $\begin{array}{l}0.67(0.64- \\
0.71)\end{array}$ & $3.0(2.4-3.6)$ & $0.6(0.5-0.7)$ \\
\hline \multicolumn{6}{|l|}{ Second period of data collection ${ }^{4}$} \\
\hline Smell disorder ${ }^{2}$ & $4.2(0.5-14.3)$ & $95.9(94.7-96.8)$ & $\begin{array}{l}0.50(0.47- \\
0.53)\end{array}$ & $1.0(0.3-4.0)$ & $1.0(0.9-1.1)$ \\
\hline Taste disorder $^{3}$ & $4.2(0.5-14.3)$ & $95.6(94.4-96.6)$ & $\begin{array}{l}0.50(0.47- \\
0.53)\end{array}$ & $0.9(0.2-3.7)$ & $1.0(0.9-1.1)$ \\
\hline Smell and taste disorder ${ }^{2,3}$ & $4.2(0.5-14.3)$ & $97.1(96.1-97.9)$ & $\begin{array}{l}0.51(0.48- \\
0.54)\end{array}$ & $1.4(0.4-5.7)$ & $1.0(0.9-1.1)$ \\
\hline Smell or taste disorder ${ }^{2,3}$ & $4.2(0.5-14.3)$ & $94.5(93.1-95.5$ & $\begin{array}{l}0.49(0.46- \\
0.52)\end{array}$ & $0.8(0.2-3.0)$ & $1.0(1.0-1.1)$ \\
\hline
\end{tabular}

${ }^{1}$ First period of data collection: March 24 to April 15, 2020

${ }^{2}$ Anosmia or hyposmia

${ }^{3}$ Ageusia or hypogeusia

${ }^{4}$ Second period of data collection: April 16 to June 9, 2020 
the two prevalence periods, limiting the probability that different diagnostic performances be due to different population characteristics.

In conclusion, the diagnostic performance of SARS-CoV-2 symptoms may vary according to the prevalence of infection as estimated by the positivity rate of screening tests. In low COVID-19 prevalence settings $(<5 \%$ ), the presence (or absence) of taste and/or smell disorders does not appear to be useful in guiding clinicians in their diagnostic approach of COVID-19. This finding should be confirmed in other primary care patient populations.

Acknowledgements: We thank all patients who accepted to participate in this study. We also thank Catherine de Beaumont, Bibiana Cardozo, Edith Corbineau, Clara Cuzin, Martin Floquet, Jean Pascal Fournier, Maeva Jego, Maud Laprée, Julie Lourdaux, Amir Moussa, and Benoit Tudrej, as well as Cerballiance Part-Dieu and Etats-Unis laboratories' teams and the Villon microbiology platform, for their assistance.

Data Availability: The data underlying this article will be shared on reasonable request to the corresponding author.

Paul Sebo, MD MSc ${ }^{1}$

Dagmar M. Haller, MD-PhD ${ }^{1}$

Hubert Maisonneuve, $M D^{1}$

${ }^{1}$ University Institute for Primary Care (IuMFE), Faculty of Medicine, University of Geneva,

1 , rue Michel-Servet, 1211 Geneva, Switzerland
Corresponding Author: Paul Sebo, MD MSc; University Institute for Primary Care (IuMFE), Faculty of Medicine, University of Geneva, 1, rue Michel-Servet, 1211 Geneva, Switzerland (e-mail: paulsebo@hotmail.com).

\section{Declarations:}

Ethical Approval: All methods were carried out in accordance with relevant guidelines and regulations. Informed consent was obtained from all participants. The study was approved by the Ethics Committee of the Collège National des Généralistes Enseignants (number 200423163) and the French CNIL (data protection authority).

Conflict of Interest: The authors declare that they do not have a conflict of interest.

\section{REFERENCES}

1. Tudrej B, Sebo P, Lourdaux J, et al. Self-Reported Loss of Smell and Taste in SARS-CoV-2 Patients: Primary Care Data to Guide Future Early Detection Strategies. J Gen Intern Med 2020; 35: 2502-4.

2. Lechien JR, Chiesa-Estomba CM, De Siati DR, et al. Olfactory and gustatory dysfunctions as a clinical presentation of mild-to-moderate forms of the coronavirus disease (COVID-19): a multicenter European study. Eur Arch Oto-Rhino-Laryngol 2020; 277: 2251-61.

3. Glezer I, Bruni-Cardoso A, Schechtman D, Malnic B. Viral infection and smell loss: The case of COVID-19. J Neurochem 2021; 157: 930-43.

4. Zayet S, Klopfenstein T, Mercier $\mathrm{J}$, et al. Contribution of anosmia and dysgeusia for diagnostic of COVID-19 in outpatients. Infection 2020; 49: 361-5.

Publisher's Note Springer Nature remains neutral with regard to jurisdictional claims in published maps and institutional affiliations. 